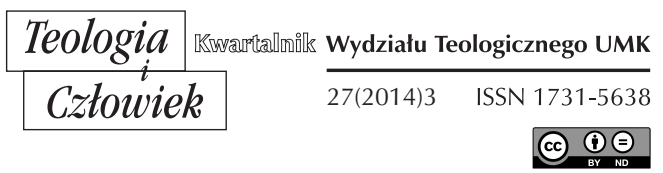

KS. WOJClECH ClCHOSZ*

TORUŃ

\title{
OD NATURY DO KULTURY. DYLEMATY I POSTULATY
}

DOI: http://dx.doi.org/10.12775/TiCz.2014.036

Kultura jest bez wątpienia zjawiskiem kształtującym się w różnych obszarach ludzkiego bytowania: indywidualnym, rodzinnym, społecznym, prawnym, wychowawczym, gospodarczym, jak również politycznym. Należy zatem na samym wstępie zapytać, czym jest kultura i jak należy ją postrzegać? Definicja podana przez autorów Encyklopedii katolickiej określa ją jako „całokształt materialnego i duchowego dorobku ludzkości, wynik twórczej działalności człowieka oraz zespół norm i zasad obowiązujących w danej zbiorowości"1. Oznacza to, że kultura jest całokształtem ludzkich zachowań, działań i ich wytworów, ma również charakter historyczny, jest bowiem przekazywana $\mathrm{z}$ pokolenia na pokolenie $^{2}$. W adhortacji

* Ks. Wojciech Cichosz - dr hab. nauk teologicznych w zakresie katechetyki i pedagogiki religii (UKSW 2010) i dr teologii apostolstwa (UKSW 2005). Obecnie kierownik Katedry Pedagogiki, Katolickiej Nauki Społecznej i Prawa Kanonicznego, członek Komisji ds. Rozwoju i Strategii oraz Komisji ds. Nagród, Orderów i Odznaczeń Państwowych Wydziału Teologicznego Uniwersytetu Mikołaja Kopernika w Toruniu, profesor nadzwyczajny w Wyższej Szkole Komunikacji Społecznej w Gdyni, Radca ds. Formacji w Zespole Szkół Katolickich im. Jana Pawła II w Gdyni.

${ }^{1}$ Encyklopedia katolicka, t. 10, Towarzystwo Naukowe KUL, Lublin 2004, s. 188.

${ }^{2}$ Zob. W. Cichosz, Możliwości dialogu wychowania chrześcijańskiego ze wspótczesna edukacja polska, Wyd. Bernardinum, Pelplin 2013, s. 151. Przywołana w tym miejscu 
apostolskiej Christifideles laici Jan Paweł II zauważa, że „służba na rzecz osoby i ludzkiego społeczeństwa wyraża się i urzeczywistnia w tworzeniu i przekazywaniu kultury, co - zwłaszcza w naszych czasach - stanowi jedno z najpoważniejszych zadań ludzkiego współżycia i społecznego rozwoju"3. Potocznie postrzegana kultura, jako dziedzina twórczości artystycznej, stanowi jedynie pewien wycinek kultury ludzkiej. Trzeba też zauważyć, że oddziaływanie kultury jest dwukierunkowe, gdyż tak jak człowiek tworzy kulturę, tak i ten, przebywając w określonej kulturze, czerpie $\mathrm{z}$ niej wzorce ${ }^{4}$. $\mathrm{Na}$ ten aspekt omawianego zagadnienia zwrócił uwagę podczas przemówienia w siedzibie UNESCO Jan Paweł II, stwierdzając, że

kultura jest właściwym sposobem bytowania człowieka. Człowiek bytuje zawsze na sposób jakiejś kultury sobie właściwej, która z kolei stwarza pomiędzy ludźmi właściwą dla nich więź, stanowiąc o międzyludzkim i społecznym charakterze ludzkiego bytowania. Stąd też w jedności kultury, jako właściwego sposobu istnienia człowieka, bierze zarazem początek wielość kultur, wśród których człowiek bytuje. W tej wielości człowiek rozwija się, nie tracąc kontaktu z jednością kultury jako podstawowego i istotnego wymiaru swego istnienia i bytowania ${ }^{5}$.

\section{KLASYCZNE I WSPÓłCZESNE ROZUMIENIE KULTURY}

W swoim pierwotnym znaczeniu termin „kultura” (łac. cultura) ograniczał się do określenia "uprawa roli” (łac. cultus agri). Jednak już Platon (427-347 przed Chr.) miano kultury odnosił do sztuki, filozofii, teologii i języka, Arystoteles (384-322 przed Chr.) zaś upatrywał w niej

pozycja bibliograficzna w całości została poświęcona współczesnym przemianom kulturowym dokonującym się w polskiej przestrzeni edukacyjnej. Kluczowe zagadnienie kultury szczegółowo omówiono w rozdziale drugim (s. 147-182). Na potrzeby niniejszego opracowania wykorzystano rozważania na temat głównych rysów i dominant dokonujących się $\mathrm{w}$ tym obszarze rekonfiguracji.

${ }^{3}$ Jan Paweł II, Posynodalna adhortacja apostolska Christifideles laici o powołaniu i misji świeckich w Kościele i w świecie dwadzieścia lat po Soborze Watykańskim II, Rzym 1988, 44.

${ }^{4}$ Zob. W. Piwowarski, Kultura, w: tenże (red.), Stownik katolickiej nauki społecznej, Instytut Wydawniczy PAX, Warszawa 1993, s. 91.

${ }^{5}$ Jan Paweł II, Przyszłość człowieka zależy od kultury. Przemówienie wygłoszone 2 czerwca 1980 roku w UNESCO, „Więż” (1980) nr 7-8, n. 6. 
siłę katartyczną (gr. katharsis), pozwalającą na wyrażenie siebie, własnych odczuć i problemów. Znaczenie pojęcia wzbogacił w I wieku p.n.e. Marcus Tullius Ciceronis (106-43 przed Chr.), gdy w Tusculanae Disputationes pisał o filozofii jako uprawie i kulturze ducha (łac. cultura animi - kultura umysłu) następująco: „Atque, ut in eodem simili verser, ut ager, quamvis fertilis, sine cultura fructuosus esse non potest; sic sine doctrina animus; ita est utraque res sine altera debilis. Cultura autem animi philosophia est: haec extrahit vitia radicitus et praeparat animos ad satus accipiendos eaque mandat iis et, ut ita dicam, serit, quae adulta fructus uberrimos ferant. Agamus igitur, ut coepimus" ${ }^{\prime \prime}$. Stwierdzał przy tym, że korzeni kultury należy szukać u starożytnych Greków - Ateńczyków: „primus agriculturae rationem Graeciam docuisse Atheniensibusque leges tulisse traditur"7 ${ }^{\prime \prime}$ Niewątpliwie w starożytnej Grecji tożsama kulturze była pedagogia (gr. paidea), obejmująca całościowe wychowanie człowieka i mająca na względzie określony ideał wychowawczy określany terminem kalokagathia ${ }^{8}$. Tak zatem w starożytności kultura nieodłącznie wiązała się $\mathrm{z}$ wychowaniem osoby i w tym znaczeniu pojęcie funkcjonowało do XVII wieku.

W 1688 roku Samuel Pufendorf w publikacji De iure naturae et gentium użył terminu „kultura” w nowoczesnym rozumieniu, dla określenia sumy wszystkich wynalazków stworzonych przez człowieka. Należy zauważyć, że przez dwa stulecia za twórcę szerszego rozumienia tego pojęcia uważano J. G. Herdera, który w Ideen zur Philosophie der Geschichte der Menschheit (1784-1791) posłużył się formą Kultur. Teoria niemieckiego filozofa, zakładająca, że język, którym Bóg obdarzył człowieka, stanowi źródło ludzkiego rozumu i kultury, zyskała wielu zwolenników. Kolejny przełom w definicji kultury stanowi utrata jednolitej struktury tego słowa na rzecz koncepcji pluralizmu kultur, które choć sobie rów-

${ }^{6}$ Cyceron w Rozprawach tuskulańskich następująco wyraża się o pierwszej w literaturze koncepcji filozofii (cultura animi - uprawa umysłu): „Czymże bez ciebie bylibyśmy nie tylko my, ale czym byłoby w ogóle ludzkie życie? Tyś pozakładała miasta, ty rozproszonych ludzi powołałaś do życia społecznego, ty zespoliłaś ich między sobą najpierw przez wspólne osiedla, później przez małżeństwa, a wreszcie przez wspólnotę mowy i pisma. Tyś wynalazczynią praw, nauczycielką dobrych obyczajów i ładu" M. T. Ciceronis, Tusculanae Disputationes libri quinque, ed. 4, Ienae 1853, http://openlibrary.org/books/OL 14046405M/Tusculanae_disputationes (dostęp 17.04.2014), s. 191.

7 Tamże, s. 497.

${ }^{8}$ Zob. W. Cichosz, Pedagogia wiary we wspótczesnej szkole katolickiej, Wyd. Typo 2, Warszawa 2010, s. 106. 
norzędne, są jednak różne9. W XVIII wieku obok omawianego terminu pojawiło się słowo „cywilizacja”, przez które rozumiano osiągnięty przez społeczeństwo w określonej epoce poziom rozwoju, ze szczególnym uwzględnieniem poziomu kultury materialnej. Tak interpretowanemu określeniu przeciwstawiano niekiedy kulturę rozumianą jako duchową twórczość człowieka, jednak współczesny słownik języka polskiego definiuje cywilizację jako całokształt zarówno materialnego, jak i duchowego dorobku społeczeństwa „wytworzony w ciągu dziejów, przekazywany kolejnym pokoleniom", dopełniając definicję po przecinku słowem „kultura” ${ }^{\prime 10}$.

Należałoby zatem skupić się na tym, co współcześnie kryje się pod określeniem „kultura”. Okazuje się, że istnieje mnogość jej definicji, często wzajemnie sprzecznych. Trafnie ujął problem osiemnastowieczny filozof niemiecki Johann Herder, wypowiadając słowa: „Nie ma nic bardziej nieokreślonego niż słowo kultura"11. I tak, w Stowniku wspótczesnego języka polskiego zostały przywołane dwa hasła znaczeniowe: w kontekście nauk o przyrodzie oraz nauk humanistycznych i społecznych. W pierwszym odnosi się do hodowli drobnoustrojów, uprawy roli bądź samej hodowli roślin, czyli bliskim pierwotnego znaczenia tego słowa. W drugim zaś jako „ogół duchowego i materialnego dorobku ludzkości wytworzony na kolejnych etapach rozwoju historycznego, nieustannie utrwalany i wzbogacany"12, pewien poziom umiejętności i rozwoju - zwłaszcza intelektualnego, a także jako „obycie towarzyskie, ogłada, takt”13. Autorzy Stownika socjologicznego określają kulturę jako „ogół materialnych i niematerialnych wytworów człowieka, wszystko to, co nie powstało na drodze naturalnej, ale jest rezultatem działania ludzi - dzięki swoistym biologicznym i społecznym cechom gatunku ludzkiego i warunkom jego bytu"14 $^{14}$. Zdarzenia i sytuacje, które powstają niezależnie od jego inspiracji,

9 Zob. A. Kłoskowska, Kultura masowa. Krytyka i obrona, PWN, Warszawa 1964 , s. 18.

${ }_{10}$ A. Sikorska-Michalak, O. Wojniłko (red.), Stownik wspótczesnego jezzyka polskiego, t. 1, Wyd. Przegląd Reader's Digest, Warszawa 1998, s. 137.

${ }^{11}$ J. G. Herder, Przedmowa, w: tenże, Myśli o filozofii dziejów, t. 1, tłum. J. Gałecki, Warszawa 1962, s. 4.

12 A. Sikorska-Michalak, O. Wojniłko (red.), dz. cyt., s. 441.

13 Tamże.

${ }^{14}$ Zob. K. Olechnicki, P. Załęcki, Stownik socjologiczny, Wyd. Graffiti BC, Toruń 2004, s. 106. 
należy zaliczyć do natury. Tym samym definicja socjologiczna wskazuje dwa podmioty: kulturę i naturę ${ }^{15}$.

Światowej sławy polski etnolog, antropolog społeczny i socjolog Bronisław Malinowski uważał, że kultura jest „integralną całością, na którą składają się narzędzia i dobra konsumpcyjne, konstytucyjne statuty różnorakich społecznych ugrupowań, ludzkie idee i rzemiosła, wierzenia i zwyczaje"16, które istnieją - jak podają autorzy Stownika wyrazów obcych - w całych dziejach ludzkości lub „w określonej epoce i na określonej przestrzeni"17.

Niezależnie od tego, na jakim stopniu rozwoju znajduje się rozpatrywana kultura, człowiek ma do dyspozycji środki materialne, ludzkie i duchowe, które umożliwiają mu rozwiązywanie codziennych problemów wynikających z jego potrzeb organicznych i środowiskowych. Środowisko co prawda dostarcza człowiekowi niezbędnych mu środków, ale bywa też „niebezpiecznym wrogiem, dającym schronienie wielu nieprzyjacielskim mocom"18. Mieczysław A. Krąpiec dopowiada zaś, że „wszelkiego rodzaju wytwory człowieka, jako rezultat jego osobowego działania, stanowią świat kultury. Oczywiście, ludzkie przeżycia, działania i wytwory mogą być dobre lub złe i dlatego mogą tworzyć dobrą lub złą kulturę. Ale moralne kwalifikacje, pozytywne lub negatywne, nie przekreślają samego kulturowego faktu, jakim jest pochodność postępowania i wytworu od ludzkiej osoby"19.

\section{TYPY KULTURY}

Przytoczone powyżej interpretacje wskazują, że na przestrzeni wieków termin „kultura” wybrzmiewa w wielu znaczeniach, w zależności od tego, w perspektywie jakiej nauki i jakich jej aspektów jest rozpatrywany. Warto zauważyć, że autorzy przywołanego już Stownika socjologicznego wymieniają aż dwadzieścia sześć definicji ${ }^{20}$. Z kolei wybitny teolog

15 Zob. Z. Bauman, Socjologia, Wyd. Zysk i S-ka, Poznań 1996, s. 148.

${ }^{16}$ B. Malinowski, Kultura i jej przemiany, PWN, Warszawa 2000, s. 59.

17 A. Latusek (red.), Nowy stownik wyrazów obcych, Wyd. Zielona Sowa, Kraków 2004, s. 485.

${ }^{18}$ B. Malinowski, dz. cyt., s. 59.

${ }^{19}$ M. A. Krąpiec, Człowiek w kulturze, Polski Instytut Kultury Chrześcijańskiej, Warszawa 1990, s. 61.

${ }^{20} \mathrm{~W}$ Stowniku socjologicznym zostały zawarte konotacje następujących terminów: 
o. Celestyn Napiórkowski, który wspomina o około dwustu ${ }^{21}$, przyznaje priorytet definicji zawartej w Gaudium et spes:

Mianem „kultury” w sensie ogólnym oznacza się wszystko, czym człowiek doskonali i rozwija wielorakie uzdolnienia swego ducha i ciała; stara się drogą poznania i pracy poddawać sam świat pod swoją władzę; czyni bardziej ludzkim życie społeczne, tak w rodzinie, jak i w całej społeczności państwowej poprzez postęp obyczajów i instytucji, wreszcie $\mathrm{w}$ dziełach swoich $\mathrm{w}$ ciągu wieków wyraża, przekazuje i zachowuje wielkie doświadczenia duchowe i dążenia na to, aby służyły one postępowi wielu, a nawet całej ludzkości (KDK 53).

W tym znaczeniu kultura oznacza swoiste „uczłowieczanie człowieka"'22.

Mając na uwadze, jak trudno jednoznacznie zdefiniować kulturę, warto w tym miejscu wskazać główne jej typy. Znawcy zagadnienia, Alfred Kroeber i Clyde Kluckhohn, w połowie ubiegłego wieku w książce Culture. A Critical Review of Concepts and Definitions podzielili kulturę na sześć typów: 1) nominalistyczny - definicje etnologiczne (E. Tylor); 2) historyczny - przekazywanie tradycji (S. Czarnowski); 3) normatywny - wpływ norm i wzorców zachowań charakterystycznych dla danego społeczeństwa (A. Kroeber, T. Parsons); 4) psychologiczny - uczenie się i naśladownictwo jako procesy przyswajania kultury (S. Ossowski); 5) strukturalny - struktura konkretnej kultury; 6) genetyczny - wyjaśnia jej pochodzenie $^{23}$. Z kolei Louis J. Luzbetak dokonuje klasyfikacji według modeli, wśród których wyróżnia: 1) modele materialistyczne (Edward B. Tylor i Lewis H. Morgan, James Frazer, Leslie White, Andrew Vayda, Roy

kultura: alternatywna, chłopska, duchowa (niematerialna), elitarna (wyższa), homogeniczna, idealna, jawna, kofiguratywna, ludowa, masowa, materialna, młodzieżowa, narodowa, polityczna, popularna, populistyczna, postfiguratywna, prefiguratywna, realna, rzeczywistości, symboliczna, świecka, techniczna, ubóstwa, ukryta, wartości - zob. K. Olechnicki, P. Załęcki, dz. cyt., s. 106-109.

${ }^{21}$ Wartości chrześcijańskie we wspótczesnej Europie, http://ekai.pl/wydarzenia/ wywiad/x48318/wartosci-chrzescijanskie-we-wspolczesnej-europie/?print=1 (dostęp 17.04.2014). Gwoli ścisłości należy zauważyć, że A. L. Kroeber i C. Kluckhohn ponad pół wieku temu zebrali niemal trzysta definicji kultury, a sto sześćdziesiąt cztery z nich przeanalizowali - zob. A. L. Kroeber, C. Kluckhohn, Culture. A Critical Review of Concepts and Definitions, Pub. Kraus Reprint Co., New York 1978.

${ }^{22}$ Zob. W. Cichosz, Pedagogia, s. 103.

${ }^{23}$ Zob. A. L. Kroeber, C. Kluckhohn, dz. cyt. 
Rappaport, Marvin Harris); 2) antropologię historyczną; 3) funkcjonalizm (Bronisław Malinowski); 4) antropologię psychologiczną (Ruth Benedict); 5) modele ideacyjne (Claude Lévi-Strauss i inni) ${ }^{24}$.

Kultura jest też systematyzowana jako: wartościująca (kulturalna) i opisowa (kulturowa); duchowa, materialna i społeczna; estetyczna (wysoka) i masowa; narodowa i regionalna; materialna i niematerialna; a nawet jako subkultura, popkultura i kontrkultura oraz wiele innych ${ }^{25}$. Przytoczone tu hasła bynajmniej nie wyczerpują terminologii związanej z kulturą, co wskazuje na to, że dotyczy ona niezwykle szerokiego zakresu ludzkiej aktywności. Różnorodność i wielość definicji kultury dowodzi, że termin i to, co w sobie kryje, stanowi ważki element ludzkiej egzystencji.

\section{OSOBOWY WYMIAR KULTURY CHRZEŚCIJAŃSKIEJ}

Kulturę widzianą oczami wiary trafnie oddają słowa z Księgi Rodzaju. Bóg, stwarzając człowieka, umieszcza go w uprzednio uformowanym środowisku, które ma "czynić sobie poddanym” (Rdz 1,28). Warto $\mathrm{w}$ tym miejscu przypomnieć, że to zadanie powierzone człowiekowi przez Boga w chwili stworzenia nie ma na względzie jedynie panowania "nad rybami morskimi, nad ptactwem powietrznym i nad wszystkimi zwierzętami pełzającymi po ziemi” (Rdz 1,28). Uczynienie ziemi „sobie poddaną" wykracza poza uprawę kultury w sensie rolniczym, ma bowiem na względzie „uprawę", której celem jest kształtowanie siebie i świata w wymiarze materialnym, cywilizacyjnym i duchowym ${ }^{26}$. Istota ludzkiej kultury polega nie tylko na kreowaniu i zgłębianiu świata zewnętrznego - podobny proces, poprzez spotkanie z drugim człowiekiem, przebiega w jego wnętrzu ${ }^{27}$. To kultura jest swoistym spoiwem, które społeczeństwo łączy w naród i jest wyrazem jego tożsamości. Naród bowiem „istnieje «z kultury» i «dla kultury» - dlatego właśnie jest ona tym wielkim wy-

${ }^{24}$ Zob. L. J. Luzbetak, Kościót a kultury. Nowe perspektywy w antropologii misyjnej, tłum. S. Kotarski, Wyd. Verbum, Warszawa 1998, s. 149-241.

${ }^{25}$ Zob. K. Olechnicki, P. Załęcki, dz. cyt., s. 106-109; J. Gevaert, Kultura (a katecheza), w: R. Szpakowski (red.), Stownik katechetyczny, tłum. K. Kozak, Wyd. Salezjańskie, Warszawa 2007, s. 535.

${ }^{26}$ Zob. K. Rahner, H. Vorgrimler, Mały stownik teologiczny, tłum. T. Mieszkowski, P. Pachciarek, Wyd. PAX, Warszawa 1996, s. 200.

27 Zob. Jan Paweł II, Pamięć i tożsamość, Wyd. Znak, Kraków 2005, s. 86-87. 
chowawcą ludzi do tego, aby «bardziej być» we wspólnocie, która ma dłuższą historię niż każdy człowiek i własna rodzina - zarazem zaś we wspólnocie, w oparciu o którą każda rodzina wychowuje, poczynając od tego, co najprostsze: od języka, którym mały człowiek uczy się mówić, aby stawać się członkiem tej wspólnoty, którą jest jego rodzina i jego naród"28. Człowiek jako podmiotowe ,ja” istnieje w samotności, z której może wyjść i wkroczyć na drogę osobowej relacji z drugim ,ja”, tym samym żyje w pewnej przestrzeni społecznej. Zdolność nawiązania relacji „,ja" - "ty" przejawia się w aktywności człowieka na zewnątrz i ma charakter twórczy, który jest "zawsze pewną propozycją dialogu z innymi i ma charakter osobowy ${ }^{\prime 29}$. Kultura jest zatem humanizacją i personalizacją bytu ludzkiego oraz świata, a jej elementem konstytutywnym jest „uczłowieczanie” życia ${ }^{30}$. Tak opisana specyfika kultury uzdalnia do głębszego wejrzenia w istotę kultury postrzeganej jako „całokształt

${ }^{28}$ Tenże, Przyszłość człowieka zależy od kultury, n. 14.

${ }^{29}$ Nietrudno zgodzić się z twierdzeniem, że człowiek może stać się w pełni człowiekiem (osobą) tylko w kontakcie i relacji z drugim. Każda osoba ludzka, jako byt zintegrowany, ze swej istoty stara się komunikować z innymi osobami, aby je poznać i kochać. Dla osobowości ludzkiej istotne jest szukanie dialogu (gr. dia - dwa i logos - słowo), w którym osobowość ta rzeczywiście może siebie dawać i w którym jest przyjmowana. Człowiek w spotkaniu z drugim człowiekiem odkrywa, że jest osobą i że musi uznać taką samą, równą jego własnej godności - godność innych ludzi. „Osoba - pisze Józef Tischner - musi być bytem-dla-siebie - bytem wewnętrznie zapośredniczonym - musi konstytuować siebie poprzez inny byt-dla-siebie. Byt-dla-siebie staje się sobą poprzez inne bycie-dla-siebie. Jestem dla-siebie poprzez ciebie. I ty jesteś dla-siebie poprzez mnie. To «poprzez» stwarza napięcia, może bowiem oznaczać: «dzięki», «na przekór», «wbrew» itp." - zob. J. Tischner, Spór o istnienie człowieka, Wyd. Znak, Kraków 1999, s. 219; K. Wojtyła, Miłość i odpowiedzialność, Wyd. KUL, Lublin 1982, s. 61-84; tenże, Osoba i czyn oraz inne studia antropologiczne, WN KUL, Lublin 1994; Jan Paweł II, Mężczyzna i niewiasta stworzyt ich. Chrystus odwotuje się do początku, Redakcja Wydawnictw KUL, Lublin 1981; J. Tischner, Myślenie wedtug wartości, Wyd. Znak, Kraków 2000, s. 162-165; J. Maritain, Osoba ludzka i społeczeństwo, w: F. Adamski (red.), Człowiek - wychowanie - kultura. Wybór tekstów, Wyd. WAM, Kraków 1993, s. 47; T. Styczeń, Człowiek w polu odpowiedzialności za siebie i drugich, "Communio" (1982) nr 2, s. 45-69; S. Napierała, Kultura - wypowiedź człowieka jako osoby. Stowo podczas Mszy św. Na inaugurację XV Forum Szkót Katolickich, 19 listopada 2004, w: J. Dobrzyńska (red.), Osobowy wymiar kultury. Materiaty XV Ogólnopolskiego Forum Szkót Katolickich. Jasna Góra, 18-20 listopada 2004, Wyd. Rada Szkół Katolickich, Warszawa 2004, s. 10-11. Rozumienie i miejsce osoby we wspólnocie społecznej i Kościoła jest tematem przewodnim tomu 16 „Kolekcji Communio” z 2004 roku.

30 Zob. Cz. Bartnik, Teologia kultury, Wyd. Standruk, Lublin 1997, s. 20; W. Cichosz, Pedagogia, s. 253-254. 
dorobku materialnego i duchowego ludzkości wytworzonego w ogólnym rozwoju historycznym lub w jego określonej epoce. Prezentowany przez kogoś wysoki poziom, zwłaszcza pod względem intelektualnym i moralnym [...]. Stopień doskonałości, sprawności w opanowaniu, znawstwie jakiejś specjalności, umiejętności itp." ${ }^{131}$ Trafnie oddaje sens terminu definicja Josepha Gevaerta, zawarta w słowach: „Kultura w szerokim znaczeniu tego słowa odnosi się do całej rzeczywistości tworzonej lub przekształcanej przez człowieka w perspektywie doskonalenia własnego człowieczeństwa"32.

Na rozwój kultury, zwłaszcza w zakresie ukazywania wartości, znacząco oddziałuje religia. Należy jednak zdecydowanie podkreślić, że kultura i religia nie są tożsame. Kultura korzysta z natury i świata, wiara zaś ma swoje źródło $\mathrm{w}$ transcendencji. $Z$ tego względu uważa się, że religia nie wyrasta z kultury, nie jest przez nią określana ani też nie jest jej częścią 33 . Wartości wpływają bowiem na charakter życia jednostek i całych społeczeństw. Skupiając uwagę na przymiotniku "chrześcijańska”, należy podkreślić, że łączy się ona z określoną kulturą: „najpierw semicką, potem helleńską i rzymską, jednak w swej istocie nie jest związana z jedną kulturą, bo chce odwoływać się do kultury każdego narodu. Określenie kultury jako chrześcijańskiej wskazuje na obecność i rolę wiary chrześcijańskiej w jej formowaniu i na względną zgodność społecznie uznawanej hierarchii wartości z wartościami głoszonymi przez Ewangelię"34. Korzystanie z kultury i sztuki ma wartość wówczas, gdy dotyczy konkretnego człowieka - jego osoby i przeżywanej przez niego kultury ${ }^{35}$. W zastanym świecie antidotum na egzystencjalne i moralne osamotnienie może stanowić powrót do klasycznego pojęcia kultury, rozumianej jako uprawa umysłu, by wzrastał w cnotach i pozbywał się wad (łac. cultura animi, cultus animi) ${ }^{36}$. W tej perspektywie nauka staje się kulturą pojmowaną jako uprawa rozumu, zdolnego do poznawania prawdy.

31 E. Sobol (red.), Maty stownik jezzyka polskiego, PWN, Warszawa 2000, s. 385.

32 J. Gevaert, dz. cyt., s. 535.

${ }_{33}$ Zob. M. Rusecki, Fenomen i tajemnica religii, w: Być chrześcijaninem, Wyd. KUL, Lublin 2006, s. 26-30.

${ }^{34}$ W. Piwowarski, dz. cyt., s. 91-92.

${ }^{35}$ Zob. I. Popiołek-Rodzińska, Wychowanie przez sztukę, w: W. Kubik (red.), Ku petni człowieczeństwa, Wyd. WAM, Kraków 1997, s. 33.

${ }^{36}$ Zob. P. Jaroszyński, Nauka w kulturze, Polskie Wydawnictwo Encyklopedyczne, Radom 2002, s. 323. 
Niewątpliwie należy pamiętać, że to człowiek, jako istota rozumna, wolna i twórcza, jest twórcą kultury, która w wychowaniu personalistycznym odgrywa istotną rolę $\mathrm{w}$ procesie doskonalenia osoby $\mathrm{w}$ jej pełnym wzrastaniu. Jest jednak również narzędziem, środkiem w wychowaniu i nauczaniu, a nie celem - przedmiotem i celem kultury jest bowiem zawsze człowiek ${ }^{37}$. Przywołane wcześniej klasyczne ujęcie definicji kultury oznacza uzupełnianie braków natury za pomocą rozumu (łac. cultura animi). Trafnie oddają istotę znaczenia kultury dla człowieka i całych społeczeństw słowa wypowiedziane przez Jana Pawła II: „Kultura jest życiem ducha, jest kluczem otwierającym dostęp do najgłębszych i najbardziej zazdrośnie strzeżonych tajników życia ludów. Powiedzieć «kultura» znaczy wyrazić w jednym słowie tożsamość narodową, która jest duszą tych ludów i która trwa pomimo warunków niesprzyjających, wszelkiego rodzaju prób, historycznych czy naturalnych kataklizmów, jedna i spoista, żywa przez wieki"38.

\section{ZAKOŃCZENIE}

Przeprowadzone analizy jednoznacznie wskazują, że twórcza aktywność człowieka ma charakter osobowy, gdyż twórca kultury - w każdym jej rozumieniu - poprzez wytwory kultury nawiązuje dialog z innym człowiekiem. Dzieła twórców kultury, rozumianej w sensie kultury artystycznej, dostarczają wielu wzruszeń, ukazują wartości, które są bliskie autorowi dzieła, przysparzając radości odbiorcy o tyle, o ile wynikają z poczucia godności osobowej, w której zawiera się wielkość i wartość człowieka. Tak rozumiana kultura artystyczna i jej wartość dla osoby i społeczeństwa odnosi się nie tylko do tego wąskiego wycinka kultury, ale również kultury rozumianej w jej szerokim znaczeniu. Wartość kultury zawsze wynika z osobowej godności człowieka stworzonego na obraz i podobieństwo Boga. To podobieństwo do Boga stanowi odniesienie dla

${ }^{37}$ Zob. W. Cichosz, Pedagogia, s. 104-105; S. Kowalczyk, Filozofia kultury. Próba personalistycznego ujęcia problematyki, Wyd. KUL, Lublin 2005, s. 54; M. Nowak, Pedagogika personalistyczna, w: Z. Kwieciński, B. Śliwerski (red.), Pedagogika 1. Podręcznik akademicki, Warszawa 2009, s. 245.

${ }^{38}$ Jan Paweł II, Stolica Apostolska wobec problemów ludzkości. Przemówienie do Korpusu Dyplomatycznego (12 stycznia 1981 roku), "L'Osservatore Romano” (1981) nr 2, s. 6, wyd. pol. 
samego siebie i do innych członków społeczeństwa i jest fundamentem dla ludzkich norm moralnych i egzystencjalnych. Ich odrzucenie, odrzucenie Boga, prowadzi do sytuacji, że człowiek przestaje odróżniać dobro od zła, a normą staje się to, co dla niego w danym momencie wygodne ${ }^{39}$. Promowany współcześnie humanizm, oparty na „poznaniu naukowym”, wyklucza akceptowanie jakiejkolwiek wartości wyższej od człowieka, umieszczonego na szczycie drabiny bytów, niemającego nikogo nad sobą, absolutnie wolnego. Odrzucenie Boga - Absolutu pociąga za sobą deifikację człowieka, tworzenie nowej religii ${ }^{40}$. Tym samym nie można już twierdzić, że laickość jest gwarantem neutralności, pozostawiającej należną każdemu sferę wolności; jest metodą, która sama tworzy i gwarantuje wartości ${ }^{41}$.

W kulturze chrześcijańskiej trzeba wyraźnie mówić o wyprowadzaniu osoby ludzkiej z natury do kultury, rozumianej jako pełna realizacja powołania osoby ludzkiej w Bogu. To swoiste wychodzenie z biosu (gr. ßios - życie, stan natury) poprzez agos (gr. ä $\gamma \omega \varsigma$ - prowadzenie, wychowanie) i etos (gr. $\tilde{\eta} \theta o \varsigma$ - obyczaj, zwyczaj, stan kultury i system

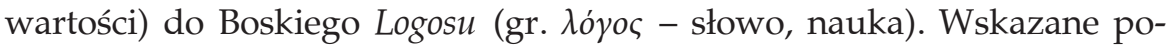
wyżej prawidłowości należy postrzegać przez pryzmat nieustannej relacji człowieka (stworzenia) do Boga (Stwórcy). Gdy zdają się powracać - używając języka biblijnego - współcześni złodzieje, rozbójnicy i drapieżne wilki, człowiek nie odczytuje swojego istnienia jedynie w perspektywie łacińskiego sum (statyczne ,jestem"), ale sursum (relacyjne, dynamiczne „w górę"), to znaczy - osoba ludzka w kulturze chrześcijańskiej nieustannie wzrasta i dąży do samorealizacji, a ostatecznie - do zjednoczenia z Bogiem ${ }^{42}$.

39 Zob. W. Cichosz, Pedagogiczny dekalog formacji chrześcijańskiej w epoce globalizmu, w: Cz. Rychlicki, I. Webiński (red.), Veritas cum Caritate - Intellegentia cum amore, Wyd. Naukowe Uniwersytetu Mikołaja Kopernika, Toruń 2011, s. 737-738; S. Napierała, dz. cyt., s. 12 .

${ }^{40}$ Zob. J. Krasicki, Przez wiarę i nadzieję ku cywilizacji mitości, Wyd. Diecezjalne, Sandomierz 1987, s. 213.

${ }^{41}$ A. Gianni, Laickość państwa a godność człowieka. Refleksja antropologiczna, "Communio" (2007) 3 (159), s. 80.

${ }^{42}$ Zob. W. Cichosz, Pedagogia, s. 355. 
Streszczenie. Kultura jest całokształtem ludzkich zachowań, działań i ich wytworów. Ma również charakter historyczny, jest bowiem przekazywana z pokolenia na pokolenie. Potocznie postrzegana kultura, jako dziedzina twórczości artystycznej, stanowi jedynie pewien wycinek kultury ludzkiej. Oddziaływanie kultury - jak trafnie zauważył Jan Paweł II podczas przemówienia w siedzibie UNESCO - jest dwukierunkowe, gdyż tak jak człowiek tworzy kulturę, tak i ten, przebywając w określonej kulturze, czerpie z niej wzorce. Twórcza aktywność człowieka ma charakter osobowy, gdyż twórca kultury - w każdym jej rozumieniu poprzez wytwory kultury nawiązuje dialog z innym człowiekiem. Wartość kultury zawsze wynika z osobowej godności człowieka stworzonego na obraz i podobieństwo Boga. To podobieństwo do Boga stanowi odniesienie dla samego siebie i do innych członków społeczeństwa i jest fundamentem dla ludzkich norm moralnych i egzystencjalnych. Ich odrzucenie, odrzucenie Boga, prowadzi do sytuacji, że człowiek przestaje odróżniać dobro od zła, a normą staje się to, co dla niego w danym momencie wygodne. Na rozwój kultury, zwłaszcza w zakresie ukazywania wartości, znacząco oddziałuje religia. Wartości wpływają bowiem na charakter życia jednostek i całych społeczeństw. We współczesnym świecie powrót do klasycznego pojęcia kultury, rozumianej jako uprawa umysłu - by ten wzrastał w cnotach i pozbywał się wad - może stanowić antidotum na egzystencjalne i moralne osamotnienie człowieka. W tej perspektywie nauka staje się kulturą pojmowaną jako uprawa rozumu, zdolnego do poznawania prawdy. Kulturę należy zatem zawsze postrzegać przez pryzmat nieustannej relacji człowieka (stworzenia) do Boga (Stwórcy).

Słowa kluczowe: kultura; natura; wartości; personalizm; normy moralne; osoba ludzka.

Summary: From nature to culture. Dilemmas and postulates. The present time is undoubtedly a period of dynamic and overwhelming cultural changes. They permeate into all fields of human life, and are especially noticeable in the system of values. Every man is born and grows in a particular culture, hence his formation cannot be accomplished in separation from the culture (lat. cultura animi). Extraordinary possibilities emerging from very dynamic scientific and technological development have resulted in man's more and more common belief that we have an unlimited power not only over nature, but also over other human beings. An attitude like that is dangerously close to usurping divine authority. A type of a cult of knowledge analysed in the article cannot become a kind of a façade, behind which hides post-modernist ideology which is destroying man and his culture and which explains contemporary changes through the negation of man in his transcendental dimension, a programmed atheism, and intellectual manipulation. Therefore in the field of culture we should above all talk about the so-called Christian hermeneutics of continuation, which leads to being faithful to God and to man. It is precisely the spiritual dimension of human life that plays an important role in overcoming the nihilism present in contemporary culture, and the values emerging from the 
Gospel and Christian culture give a great opportunity for a beneficial influence on moral and ethical attitudes. The principles of the culture described above must be perceived from the angle of the constant relation of man (the creation) to God (the Creator).

Keywords: culture; nature; values; personalism; moral norms; human person. 
